\title{
Chemical and Free Radical-scavenging Activity Changes of Ginsenoside Re by Maillard Reaction and Its Possible Use as a Renoprotective Agent
}

\author{
Noriko Yamabe ${ }^{1 \#}$, Kyung Il Song ${ }^{2 \#}$, Woojung Lee ${ }^{3}$, Im-Ho Han ${ }^{3}$, Ji Hwan Lee ${ }^{3}, J_{u n g y e o b ~ H a m}{ }^{3}$, \\ Su-Nam Kim ${ }^{3}$, Jeong Hill Park ${ }^{4}$, and Ki Sung Kang ${ }^{3 *}$ \\ ${ }^{1}$ Institute of Natural Medicine, University of Toyama, Toyama 930-0194, Japan \\ ${ }^{2}$ Department of Internal Medicine, Gangneung Asan Hospital, University of Ulsan College of Medicine, Gangneung 210-711, \\ Korea \\ ${ }^{3}$ Natural Medicine Center, Korea Institute of Science and Technology, Gangneung 210-340, Korea \\ ${ }^{4}$ Research Institute of Pharmaceutical Sciences and College of Pharmacy, Seoul National University, Seoul 151-742, Korea
}

Reactive oxygen species play critical role in kidney damage. Free radical-scavenging activities of Panax ginseng are known to be increased by heat-processing. The structural change of ginsenoside and the generation of Maillard reaction products (MRPs) are closely related to the increased free radical-scavenging activities. In the present study, we have demonstrated the Maillard reaction model experiment using ginsenoside Re and glycine mixture to identify the renoprotective effect of MRPs from ginseng or ginsenosides. Ginsenoside Re was transformed into less-polar ginsenosides, namely $\operatorname{Rg} 2, \operatorname{Rg} 6$ and F4 by heat-processing. The free radical-scavenging activity of ginsenoside Re-glycine mixture was increased in a temperature-dependant manner by heatprocessing. The improved free radical-scavenging activity by heat-processing was mediated by the generation of antioxidant MRPs which led to the protection of LLC-PK1 renal epithelial cells from oxidative stress. Although the free radical scavenging activities of less-polar ginsenosides were weak, they could protect LLC-PK1 cells from oxidative stress. Therefore, MRPs and less-polar ginsenosides contributed to the combined renoprotective effects against oxidative renal damage.

Keywords: Panax ginseng, Maillard reaction, Ginsenoside, Reactive oxygen species, Renoprotective effect

\section{INTRODUCTION}

The free radical-scavenging activities of Panax ginseng Meyer (Araliaceae) increased by heat-processing [13]. Ginsenosides have been regarded as the main active components of $P$. ginseng, and we have identified that the structural changes of ginsenosides by heat-processing are closely related to its increased free radical-scavenging activities $[4,5]$. In addition, the generation of Maillard reaction products (MRPs), although limited to the reaction between the glucosyl moieties separated from ginsenosides and glycine, is positively correlated with the free

(c) This is an Open Access article distributed under the terms of the Creative Commons Attribution Non-Commercial License (http://creativecommons.org/licenses/by-nc/3.0/) which permits unrestricted non-commercial use, distribution, and reproduction in any medium, provided the original work is properly cited. radical-scavenging activity [6].

The kidney plays important roles not only in excreting waste products, but also in maintaining electrolyte and water balance. Recent literature indicates that reactive oxygen species (ROS) play critical roles in the development and progression of kidney damage $[7,8]$. For example, in the diabetic kidney, there are a number of enzymatic and nonenzymatic sources of ROS, including the autoxidation of glucose, transition metal-catalyzed Fenton reactions, advanced glycation, mitochondrial

\footnotetext{
Received 02 Mar. 2012, Revised 16 Apr. 2012, Accepted 17 Apr. 2012

"These two authors contributed equally to this work.

*Corresponding author

E-mail: kkang@kist.re.kr

Tel: +82-33-650-3512, Fax: +82-33-650-3028
} 
respiratory chain deficiencies, and nicotinamide adenine dinucleotide phosphate (NADPH) oxidase [7,9,10].

We have previously identified that ginseng sapogenins, which are aglycone parts of ginsenosides, have a protective effect against oxidative damage by radical generator, 2,2'-azobis (2-amidinopropane) dihydrochloride (AAPH) in renal epithelial LLC-PK cells [11]. In addition, ginsenosides $\mathrm{Rh} 4$ and $\mathrm{Rk} 3$, which were generated much after heat-processing, significantly reduced the cisplatininduced nephrotoxicity in LLC-PK1 cells [12]. However, little is known about the renoprotective effect of MRPs from ginseng or ginsenosides.

MRPs are known as a major source of compounds related to enhanced antioxidant activity by heat treatment in various crude drugs or foods [13-15]. The aim of the present study was to identify the renoprotective effect and mechanism of MRPs from ginseng.

\section{MATERIALS AND METHODS}

\section{Chemicals and reagents}

1,1-Diphenyl-2-picrylhydrazyl (DPPH), AAPH, 3-(4,5-Dimethyl-2-thiazolyl)-2,5-diphenyl-2H tetrazolium bromide (MTT) were purchased from Sigma Aldrich (Seoul, Korea). Dulbecco's modified Eagle's medium/ nutrient mixture F-12 and fetal bovine serum were purchased from Invitrogen Co. (Grand Island, NY, USA). Ginsenoside Re was isolated and identified from $P$. ginseng by the reported method [16]. The other chemicals and reagents used were of high quality and obtained from commercial sources.

\section{Maillard reaction model experiment using ginsen- oside Re and glycine}

The same amounts (w/w) of ginsenoside Re and glycine, a frequently used amino acid in Maillard reaction model experiment, were steamed together at $120^{\circ} \mathrm{C}$ for $3 \mathrm{~h}$ as reported previously. After drying at $50^{\circ} \mathrm{C}$ for $3 \mathrm{~d}$, un-treated and heat-processed ginsenoside Re-glycine mixtures at $120^{\circ} \mathrm{C}$ were prepared. The glucose-glycine mixture heat-processed at $120^{\circ} \mathrm{C}$ was also prepared to examine the effect of MRPs $[5,6]$.

\section{Measurement of browning compound levels}

The extent of browning was measured by the reported method with minor modification. The samples $(5 \mathrm{mg})$ were dissolved in $1 \mathrm{~mL}$ of distilled water (DW)acetonitrile $(1: 1, \mathrm{v} / \mathrm{v})$, and the absorbance at $420 \mathrm{~nm}$ was measured in a $1 \mathrm{~cm}$ glass cuvette using a UV-Vis spectrophotometer (UV-1200; Shimadzu, Kyoto, Japan).
Measurement was repeated three for each sample [5].

\section{1,1-Diphenyl-2-picrylhydrazyl radical-scavenging activity test}

In microwells, $100 \mu \mathrm{L}$ of an aqueous solution of the sample (control: $100 \mu \mathrm{L}$ of DW) was added to an ethanolic solution of DPPH $(100 \mu \mathrm{L}, 60 \mu \mathrm{M})$ according to the method of Hatano et al. [17]. After mixing gently and leaving to stand for $30 \mathrm{~min}$ at room temperature, the absorbance at $540 \mathrm{~nm}$ was determined using a microplate reader (Tecan SPECTRAFluor; Tecan UK, Goring-onThames, UK), and a vitamin C was used as DPPH scavenging positive control compound [18].

\section{Renoprotective effect against oxidative damage in cells}

The renoprotective effect against oxidative damage was evaluated using LLC-PK1 cells [19]. Cell viability was measured using MTT-based colorimetric assay. The cells were seeded in 96-well culture plates at $10^{4}$ cells per well and allowed to adhere for $2 \mathrm{~h}$. Thereafter, the test sample and/or radical donor, $10 \mathrm{mM} \mathrm{AAPH}$, were added to culture medium, and the plates were incubated for $24 \mathrm{~h}$. Fifty microliters of MTT $(1 \mathrm{mg} / \mathrm{mL})$ solution was added to each well. After incubation for $4 \mathrm{~h}$ at $37^{\circ} \mathrm{C}$, the medium containing MTT was removed. The incorporated formazan crystals in the viable cells were solubilized with $100 \mu \mathrm{L}$ of dimethylsulfoxide. An absorbance at 540 $\mathrm{nm}$ of each well was read using a microplate reader.

\section{Analysis of ginsenosides}

Samples were analyzed with a Hitachi (Tokyo, Japan) L-7100 liquid chromatograph fitted with a C-18, reversed-phase column $(5 \mu \mathrm{m}, 25 \mathrm{~cm} \times 4 \mathrm{~mm}$ i.d.; YMCPack Pro) utilizing a solvent gradient system [6]. The mobile phase consisted of water (solvent A) and acetonitrile (solvent B) and the flow rate was $1 \mathrm{~mL} / \mathrm{min}$. The detector was a SEDEX 55 evaporative light scattering detector (Sedere, Alfortville, France). The gradient elution was used as follows: $0 \mathrm{~min}, 15 \% \mathrm{~B} ; 10 \mathrm{~min}, 40 \%$ B; $25 \mathrm{~min}, 50 \% \mathrm{~B}$; $40 \mathrm{~min}, 80 \% \mathrm{~B}$; and $50 \mathrm{~min}, 100 \%$ B. Ginsenosides were identified by the comparison of retention times with those of authentic samples, which were previously isolated in our laboratory by the reported method [16].

\section{RESULTS AND DISCUSSION}

DPPH has been widely used to test the ability of compounds or plant extracts as free radical scavengers or 
A

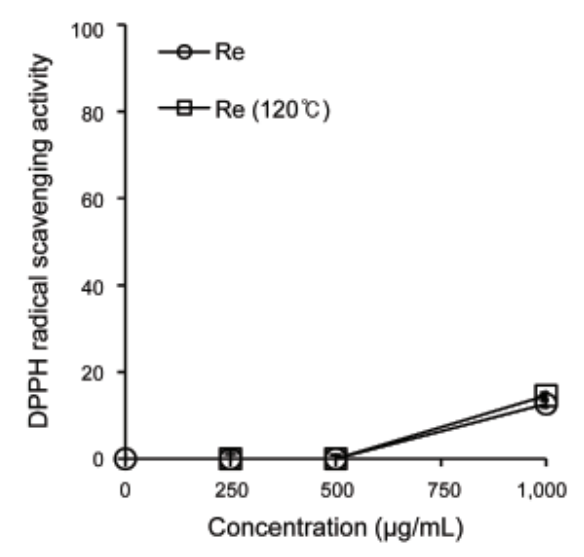

C

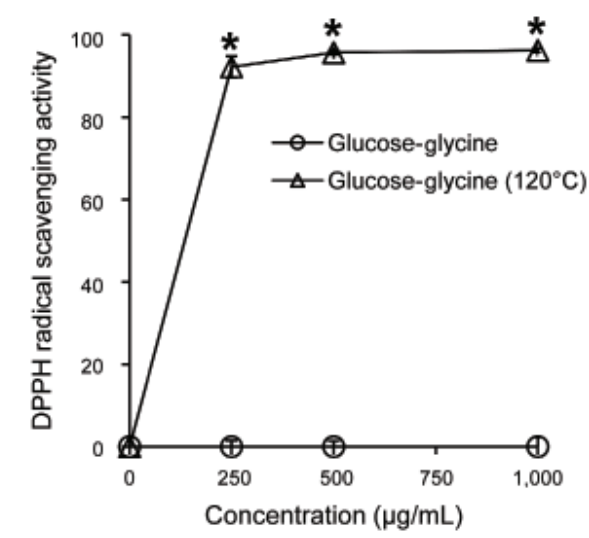

B

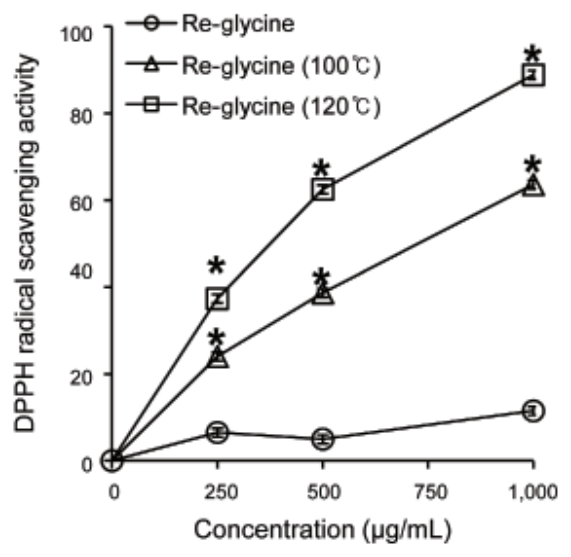

D

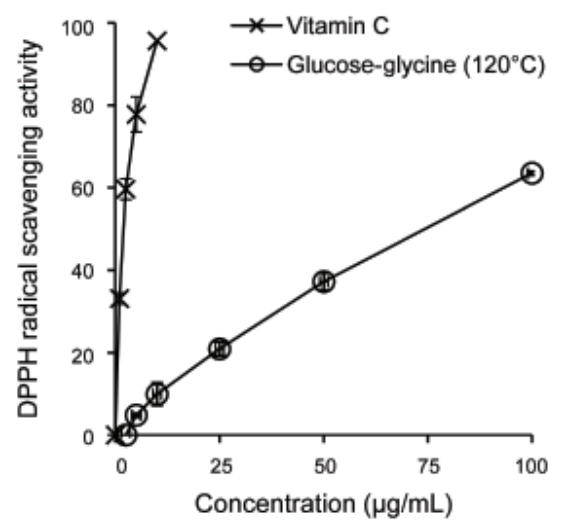

Fig. 1. The changes in 1,1-diphenyl-2-picrylhydrazyl (DPPH) radical-scavenging activity changes of ginsenoside Re by Maillard reaction. (A) Comparison in DPPH radical-scavenging activity of ginsenoside Re by heat-processing. (B) Comparison in DPPH radical-scavenging activity of ginsenoside Re-glycine mixture by heat-processing. (C) Comparison in DPPH radical-scavenging activity of glucose-glycine mixture by heatprocessing. (D) Comparison in DPPH radical-scavenging activity of heat-processed glucose-glycine mixture with vitamin $\mathrm{C}$. ${ }^{*} p<0.05$ compared to the not-treated value.

hydrogen donors $[17,20]$. From the comparison of DPPH radical-scavenging activity tests of ginsenoside $\mathrm{Re}$ and its MRPs (Fig. 1), ginsenoside Re showed weak DPPH radical-scavenging activity and its effect was not changed by heat-processing (Fig. 1A). Although the DPPH radical-scavenging activity of ginsenoside Re-glycine mixture was weak, its effect was significantly increased in a temperature-dependant manner by heat-processing (Fig. 1B). The glucose-glycine mixture has no DPPH radical-scavenging activity, but its effect was remarkably increased after heat-processing at $120^{\circ} \mathrm{C}$ (Fig. 1C). The DPPH radical-scavenging activity of glucose-glycine mixture after heat-processing was weaker than vitamin C at the same dose (Fig. 1D), but its effect was significantly stronger than that of ginsenoside Re-glycine mixture (Fig.
1B, D). Therefore, the improved free radical-scavenging activity of ginsenoside Re-glycine mixture by heat-processing is caused by MRPs, not ginsenoside derivatives.

The development of color is an obvious feature of Maillard reaction. Brown-colored nitrous polymers, called melanoidins, which have an antioxidant activity are known to be formed by this Maillard reaction [21]. The MRPs level of ginsenoside Re-glycine mixture was increased from 0.0013 to 0.0047 after heat-processing at $100^{\circ} \mathrm{C}$, and it was more significantly increased to 0.0220 after heat-processing at $120^{\circ} \mathrm{C}$ (Fig. $2 \mathrm{~A}$, left panel). In the case of glucose-glycine mixture, the MRPs level was increased to 0.310 after heat-processing at $120^{\circ} \mathrm{C}$ and it was 14.6 times higher than the value of ginsenoside Reglycine mixture (Fig. 2A, right panel). 


\section{A MRPs level}
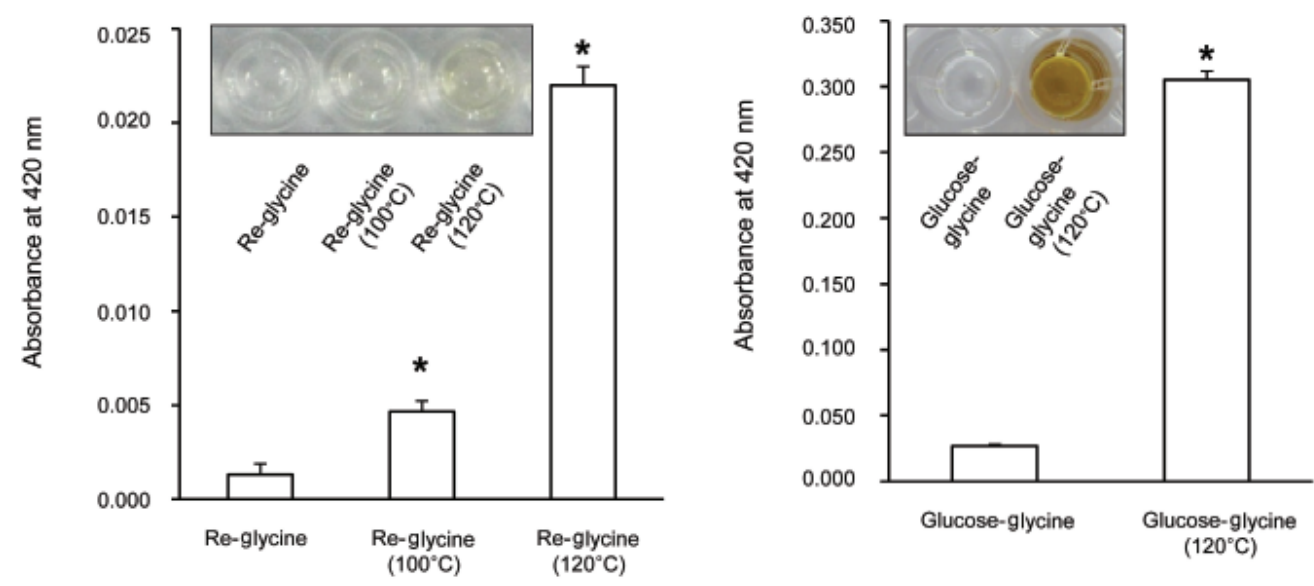

B Total phenolic contents
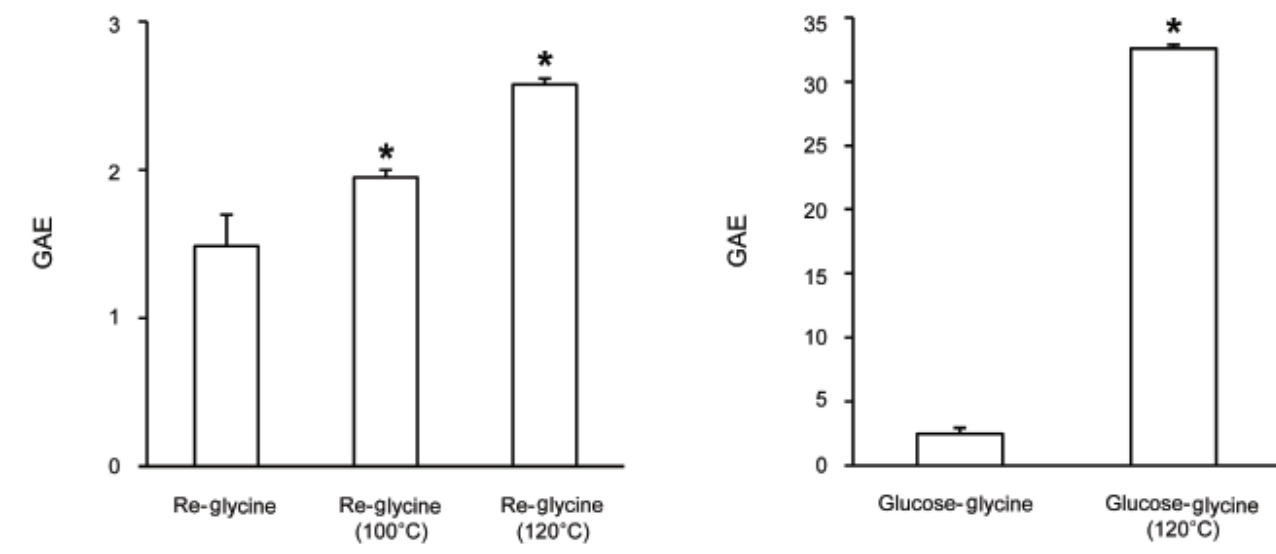

C Re-glycine

\section{Re-glycine $\left(120^{\circ} \mathrm{C}\right)$}
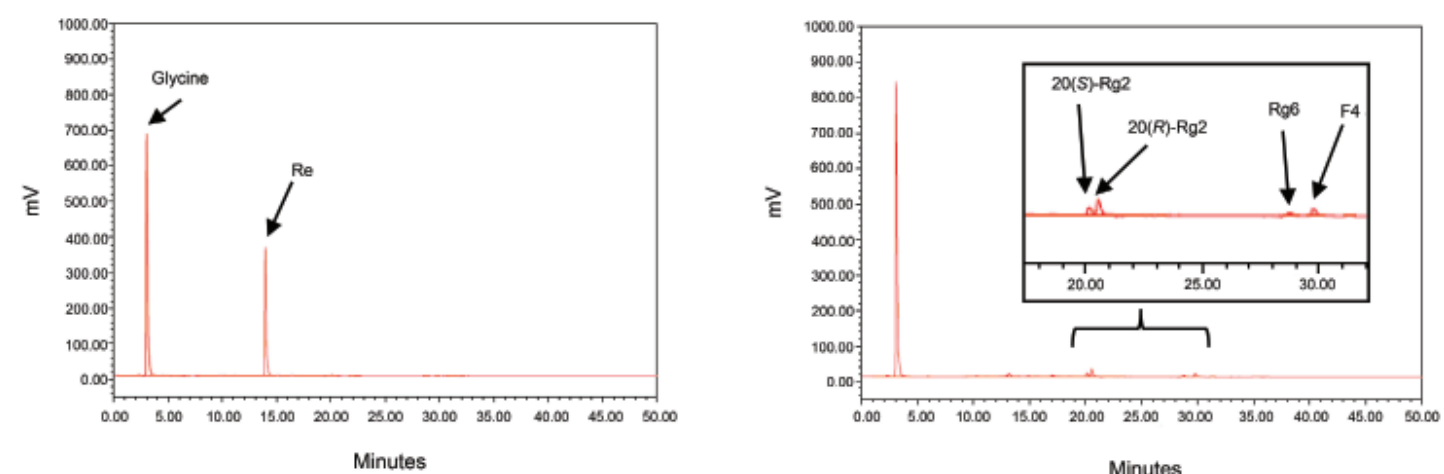

Fig. 2. Comparison of browning compound levels, total phenolic contents and HPLC chromatograms of ginsenoside Re by Maillard reaction. (A) The changes in browning compound levels of ginsenoside Re-glycine and glucose-glycine mixtures by heat-processing. (B) The changes in total phenolic contents of ginsenoside Re-glycine and glucose-glycine mixtures by heat-processing. (C) HPLC chromatogram of ginsenoside Reglycine mixture before heat-processing. (D) HPLC chromatogram of ginsenoside Re-glycine mixture after heat-processing. MRPS, Maillard reaction products; GAE, gallic acid equivalent. ${ }^{*} p<0.05$ compared to the not-treated value.

The phenolic contents of plants can influence their antioxidant activities, and MRPs are known as major contributors to enhanced antioxidant activity brought about by heat treatment in various foods [13-15]. Fig. 2B 

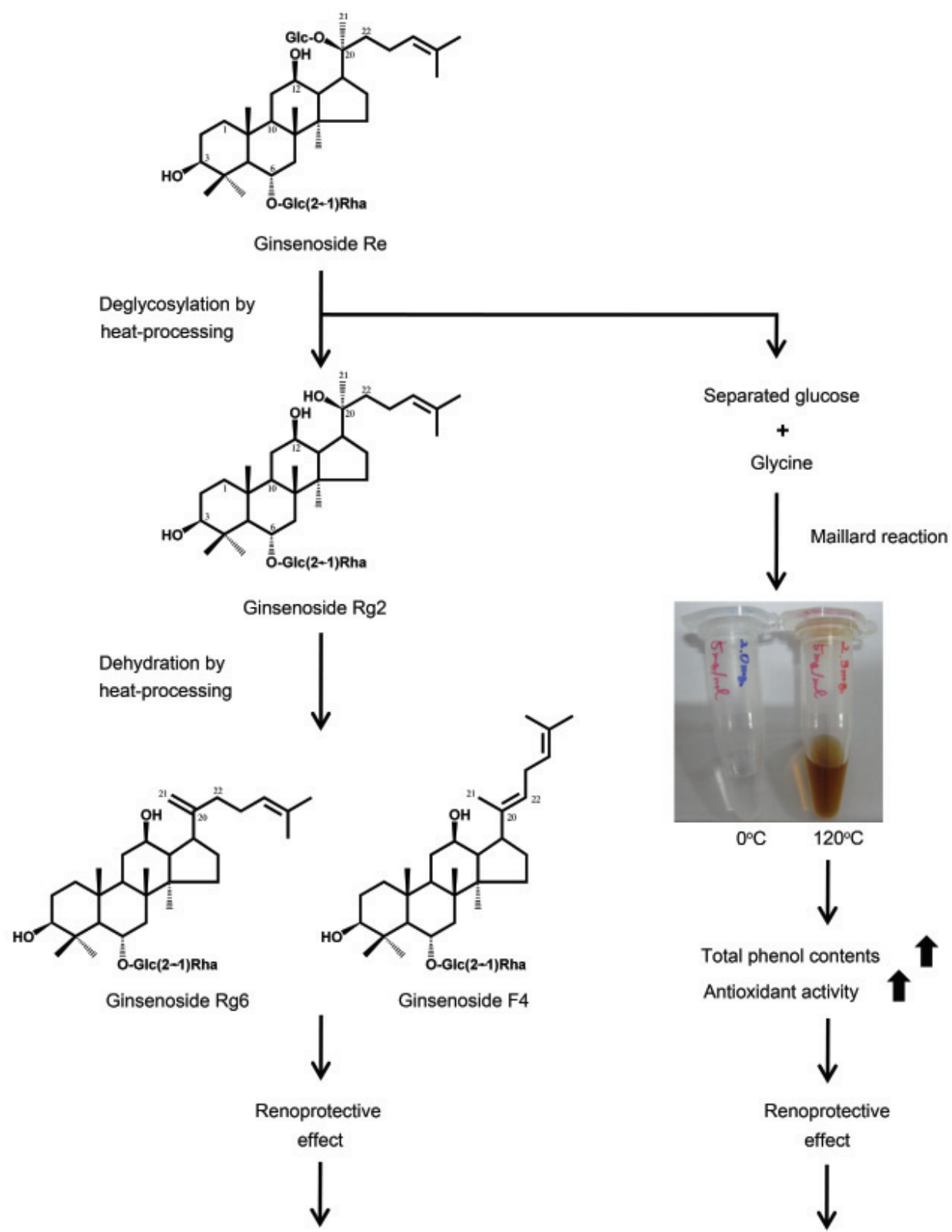

Total phenol contents

Antioxidant activity

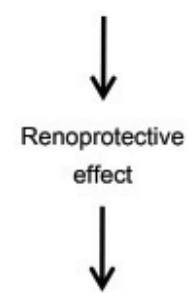

Combined renoprotective effect

by Maillard reaction

Fig. 3. Schematic representation of the combined renoprotective effects of ginsenoside Re by Maillard reaction.

shows the changes in total phenolic contents of ginsenoside Re-glycine and glucose-glycine mixtures by heatprocessing. The total phenolic content of ginsenoside Re-glycine mixture was increased in a temperaturedependant manner by heat-processing (Fig. 2B, left panel). In addition, the total phenolic content of glucoseglycine mixture was significantly increased from 2.49 to 32.59 gallic acid equivalent by heat-processing, and its value was 12.7 times higher than that of ginsenoside Reglycine mixture. The increase in total phenolic contents by heat-processing was related to the increase of MRPs.

As shown in the HPLC chromatograms of ginsenoside Re-glycine mixture and heat-processed ginsenoside Reglycine mixture, the glycine and ginsenoside Re were detected at about 3.1 and $14.0 \mathrm{~min}$, respectively, without heat-processing (Fig. 2C). Subsequently, all the ginsen- 
Table 1. Effects of ginsenoside Re and its Maillard reaction products on viability of LLC-PK1 cells treated with AAPH

\begin{tabular}{|c|c|c|}
\hline Chemicals & Concentration $(\mathrm{ug} / \mathrm{mL})$ & Cell viability $(\%)$ \\
\hline \multirow{4}{*}{$\operatorname{Re}$} & 0 & $71.7 \pm 4.1$ \\
\hline & 1 & $74.5 \pm 8.8$ \\
\hline & 3 & $77.9 \pm 11.1$ \\
\hline & 10 & $89.6 \pm 9.7^{1)}$ \\
\hline \multirow{4}{*}{$\operatorname{Re}\left(120^{\circ} \mathrm{C}\right)$} & 0 & $71.7 \pm 4.1$ \\
\hline & 1 & $88.9 \pm 0.9^{1)}$ \\
\hline & 3 & $89.9 \pm 2.7^{1)}$ \\
\hline & 10 & $93.7 \pm 4.3^{1)}$ \\
\hline \multirow{4}{*}{ Re-glycine } & 0 & $71.7 \pm 4.1$ \\
\hline & 1 & $86.1 \pm 3.9$ \\
\hline & 3 & $86.1 \pm 5.0$ \\
\hline & 10 & $74.1 \pm 6.0$ \\
\hline \multirow{4}{*}{ Re-glycine $\left(120^{\circ} \mathrm{C}\right)$} & 0 & $70.5 \pm 6.6$ \\
\hline & 1 & $72.3 \pm 7.0$ \\
\hline & 3 & $80.2 \pm 11.8$ \\
\hline & 10 & $97.6 \pm 6.4^{1)}$ \\
\hline \multirow{4}{*}{ Glucose-glycine $\left(120^{\circ} \mathrm{C}\right)$} & 0 & $71.5 \pm 0.4$ \\
\hline & 1 & $79.9 \pm 3.8$ \\
\hline & 3 & $77.7 \pm 5.7$ \\
\hline & 10 & $103.0 \pm 0.2^{1)}$ \\
\hline \multirow{4}{*}{ Aminoguanidine } & 0 & $71.7 \pm 4.1$ \\
\hline & 1 & $74.0 \pm 3.0$ \\
\hline & 10 & $86.7 \pm 14.2$ \\
\hline & 100 & $88.0 \pm 4.1^{1)}$ \\
\hline AAPH non-treatment & - & $100.0 \pm 4.0$ \\
\hline
\end{tabular}

AAPH, 2,2'-azobis (2-amidinopropane) dihydrochloride. Statistical significance: ${ }^{1)} p<0.05$ compared to the AAPH treatment control value.

oside Re disappeared, and the contents of ginsenosides $\mathrm{Rg} 2, \operatorname{Rg} 6$ and F4 were newly detected after heat-processing at $120^{\circ} \mathrm{C}$ (Fig. 2C). Ginsenoside Rg2 was suggested to be generated by the elimination of the glycosyl residue at carbon-20 during the steaming process, and more lesspolar ginsenosides such as Rg6 and F4 were produced by the elimination of $\mathrm{H}_{2} \mathrm{O}$ at carbon-20 of ginsenoside $\mathrm{Rg} 2$ under high pressure and temperature conditions like those in other ginsenosides [6]. Therefore, ginsenoside Re was gradually changed into ginsenosides $\operatorname{Rg} 2, \operatorname{Rg} 6$ and $\mathrm{F} 4$ by heat-processing.

Table 1 shows the effects of ginsenoside Re and MRPs on the viability of LLC-PK1 renal epithelial cells treated with AAPH. AAPH react with oxygen molecules rapidly to yield peroxyl radicals. The lipid peroxyl radicals attack other lipid molecules to form lipid hydroperoxide and new lipid radicals which induce cellular damages [22]. The viability of LLC-PK1 cells declined to $71.7 \%$ by $10 \mathrm{mM}$ AAPH treatment. However, the cell damage induced by oxidative stress was inhibited by the treatments with $10 \mu \mathrm{g} / \mathrm{mL}$ of ginsenoside Re, and this protective effect improved after heat-processing. Next, ginsenoside Re-glycine mixture had no effect on LLCPK1 cell damage, but the cell viability was significantly increased after heat-processing at $120^{\circ} \mathrm{C}$. In particular, 10 $\mu \mathrm{g} / \mathrm{mL}$ of glucose-glycine mixture completely recovered viability of LLC-PK1 cells to $103 \%$ and its effect was quite stronger than aminoguanidine which has a protective effect on renal damage by inhibiting oxidative stress [23]. The protective effect of MRPs on oxidative renal cell damage was suggested to be mediated by its direct free radical scavenging activity, whereas less-polar ginsenosides exert its antioxidant activity by modulating the activity of metabolizing enzymes and/or interfering with gene transcription related to oxidative stress in cells.

In summary, the free radical-scavenging activity of ginsenoside Re-glycine mixture was increased in a temperature-dependant manner by heat-processing. The improved free radical-scavenging activity by heatprocessing was mediated by the generation of antioxidant MRPs which led to the protection of LLC-PK1 renal epithelial cells from oxidative stress. Although the free radical scavenging activities of less-polar ginsenosides were weak, they also protected LLC-PK1 cells from oxidative stress (Fig. 3). Therefore, MRPs and less-polar ginsenosides contributed to the combined renoprotective effects against oxidative renal damage.

\section{ACKNOWLEDGEMENTS}

This work was funded by Gangneung Asan Hospital Biomedical Research Center Promotion Fund.

\section{REFERENCES}

1. Keum YS, Park KK, Lee JM, Chun KS, Park JH, Lee SK, Kwon H, Surh YJ. Antioxidant and anti-tumor promoting activities of the methanol extract of heat-processed ginseng. Cancer Lett 2000;150:41-48.

2. Kim WY, Kim JM, Han SB, Lee SK, Kim ND, Park MK, Kim CK, Park JH. Steaming of ginseng at high temperature enhances biological activity. J Nat Prod 2000;63:1702-1704.

3. Kim HD, Ha SE, Kang JR, Park JK. Effect of Korean Red Ginseng Extract on Cell Death Responses in Peroxynitrite-Treated Keratinocytes. J Ginseng Res 2010;34:205- 
211.

4. Kang KS, Yokozawa T, Yamabe N, Kim HY, Park JH. ESR study on the structure and hydroxyl radical-scavenging activity relationships of ginsenosides isolated from Panax ginseng C A Meyer. Biol Pharm Bull 2007;30:917921.

5. Yamabe N, Lee JG, Lee YJ, Park CH, Kim HY, Park JH, Yokozawa T, Kang KS. The chemical and 1,1-diphenyl2-picrylhydrazyl radical scavenging activity changes of ginsenosides Rb1 and Rg1 by maillard reaction. J Ginseng Res 2011;35:60-68.

6. Lee YJ, Kim HY, Kang KS, Lee JG, Yokozawa T, Park $\mathrm{JH}$. The chemical and hydroxyl radical scavenging activity changes of ginsenoside-Rb1 by heat processing. Bioorg Med Chem Lett 2008;18:4515-4520.

7. Forbes JM, Coughlan MT, Cooper ME. Oxidative stress as a major culprit in kidney disease in diabetes. Diabetes 2008;57:1446-1454.

8. Nistala R, Whaley-Connell A, Sowers JR. Redox control of renal function and hypertension. Antioxid Redox Signal 2008;10:2047-2089.

9. Li JM, Shah AM. ROS generation by nonphagocytic NADPH oxidase: potential relevance in diabetic nephropathy. J Am Soc Nephrol 2003;14:S221-S226.

10. Heyman SN, Rosen S, Rosenberger C. A role for oxidative stress. Contrib Nephrol 2011;174:138-148.

11. Kang KS, Kim HY, Yoo HH, Piao XL, Ham J, Yang HO, Park JH. Protective effect of ginseng sapogenins against 2,2'-azobis (1-aminopropane) dihydrochloride (AAPH)induced LLC-PK 1 cell damage. Bioorg Med Chem Lett 2012;22:634-637.

12. Baek SH, Piao XL, Lee UJ, Kim HY, Park JH. Reduction of Cisplatin-induced nephrotoxicity by ginsenosides isolated from processed ginseng in cultured renal tubular cells. Biol Pharm Bull 2006;29:2051-2055.

13. Morales FJ, Jimenez-Perez S. Free radical scavenging capacity of Maillard reaction products as related to colour and fluorescence. Food Chem 2001;72:119-125.

14. Yanagimoto K, Ochi H, Lee KG, Shibamoto T. Antioxida- tive activities of fractions obtained from brewed coffee. $\mathrm{J}$ Agric Food Chem 2004;52:592-596.

15. Cai Y, Luo Q, Sun M, Corke H. Antioxidant activity and phenolic compounds of 112 traditional Chinese medicinal plants associated with anticancer. Life Sci 2004;74:21572184.

16. Oura H, Hiai S, Odaka Y, Yokozawa T. Studies on the biochemical action of ginseng saponin. I. Purification from ginseng extract of the active component stimulating serum protein biosynthesis. J Biochem 1975;77:10571065.

17. Hatano T, Edamatsu R, Hiramatsu M, Mori A, Fujita Y, Yasuhara T, Yoshida T, Okuda T. Effects of the interaction of tannins with co-existing substances. VI. Effects of tannins and related polyphenols on superoxide anion radical, and on 1,1-diphenyl-2-picrylhydrazyl radical. Chem Pharm Bull (Tokyo) 1989;37:2016-2021.

18. Deng JS, Chi CS, Huang SS, Shie PH, Lin TH, Huang GJ. Antioxidant, analgesic, and anti-inflammatory activities of the ethanolic extracts of Taxillus liquidambaricola. J Ethnopharmacol 2011;137:1161-1171.

19. Yokozawa T, Cho EJ, Hara Y, Kitani K. Antioxidative activity of green tea treated with radical initiator 2, 2'-azobis(2-amidinopropane) dihydrochloride. J Agric Food Chem 2000;48:5068-5073.

20. Yun BS, Lee MR, Oh CJ, Cho JH, Wang CY, Gu LJ, Mo EK, Sung CK. Characterization of Black Ginseng Extract with Acetyl- and Butyrylcholinesterase Inhibitory and Antioxidant Activities. J Ginseng Res 2010;34:348-354.

21. Samaras TS, Camburn PA, Chandra SX, Gordon MH, Ames JM. Antioxidant properties of kilned and roasted malts. J Agric Food Chem 2005;53:8068-8074.

22. Miki M, Tamai H, Mino M, Yamamoto Y, Niki E. Freeradical chain oxidation of rat red blood cells by molecular oxygen and its inhibition by alpha-tocopherol. Arch Biochem Biophys 1987;258:373-380.

23. Abraham P, Rabi S. Protective effect of aminoguanidine against cyclophosphamide-induced oxidative stress and renal damage in rats. Redox Rep 2011;16:8-14. 